\title{
X-ray crystal structure of Vibrio alkaline phosphatase with the non-competitive inhibitor cyclohexylamine
}

\author{
Bjarni Ásgeirsson ${ }^{\mathrm{a},{ }^{*}, 1}$, Sigurbjörn Markússon ${ }^{\mathrm{a}}$, Sigríður S. Hlynsdóttir ${ }^{\mathrm{a}}$, Ronny Helland ${ }^{\mathrm{b}}$, \\ Jens G. Hjörleifsson ${ }^{a}$ \\ ${ }^{a}$ Department of Biochemistry, Science Institute, University of Iceland, Dunhagi 3, 107 Reykjavik, Iceland \\ ${ }^{\mathrm{b}}$ NorStruct, Department of Chemistry, Faculty of Science and Technology, UiT - the Arctic University of Norway, NO-9037, Troms $\phi$, Norway
}

\section{A R T I C L E I N F O}

\section{Keywords:}

Enzymology

Alkaline phosphatase

Enzyme inhibitor

$P$-nitrophenyl phosphate

Cyclohexylamine

Non-competitive

\begin{abstract}
A B S T R A C T
Background: Para-nitrophenyl phosphate, the common substrate for alkaline phosphatase (AP), is available as a cyclohexylamine salt. Here, we report that cyclohexylamine is a non-competitive inhibitor of APs.

Methods: Cyclohexylamine inhibited four different APs. Co-crystallization with the cold-active Vibrio AP (VAP) was performed and the structure solved.

Results: Inhibition of VAP fitted a non-competitive kinetic model ( $\mathrm{K}_{\mathrm{m}}$ unchanged, $\mathrm{V}_{\max }$ reduced) with $\mathrm{IC}_{50} 45.3$ $\mathrm{mM}$ at the $\mathrm{pH}$ optimum 9.8, not sensitive to $0.5 \mathrm{M} \mathrm{NaCl}$, and $\mathrm{IC}_{50} 27.9 \mathrm{mM}$ at pH 8.0, where the addition of $0.5 \mathrm{M}$ $\mathrm{NaCl}$ altered the inhibition to the level observed at $\mathrm{pH}$ 9.8. APs from $E$. coli and calf intestines were less sensitive to cyclohexylamine, whereas an Antarctic bacterial AP was similar to VAP in this respect. X-ray crystallography at $2.3 \AA$ showed two binding sites, one in the active site channel and another at the surface close to dimer interface. Antarctic bacterial AP and VAP have Trp274 in common in their active-sites, that takes part in binding cyclohexylamine. VAP variants W274A, W274K, and W274H gave $\mathrm{IC}_{50}$ values of $179 \mathrm{mM}, 188 \mathrm{mM}$ and $187 \mathrm{mM}$, respectively, at $\mathrm{pH} 9.8$.

Conclusions: The binding of cyclohexylamine in locations at the dimeric interface and/or in the active site of APs may delay product release or reduce the rate of catalytic step(s) involving conformational changes and intersubunit communications.

General significance: Cyclohexylamine is a common chemical in industries and used as a counterion in substrates for alkaline phosphatase, a clinically important and common enzyme in the biosphere.
\end{abstract}

\section{Introduction}

Alkaline phosphatases (APs; EC 3.1.3.1) are relatively nonspecific enzymes and work as ectoenzymes, either attached to the surface of animal cells, or they are excreted into the periplasmic space of bacteria [1]. In mammals, APs have an important role in bone formation and in preventing intestinal inflammation [2-7]. Recent evidence suggests that intestinal AP plays a role in determining which bacteria colonize the gut [3]. APs have also been linked with cardiovascular diseases [8-11] and Alzheimer disease [12-14], not all of which is well defined [15-18]. In bacteria, APs are believed to have the main role of harvesting nutrients in the form of inorganic phosphate under conditions of phosphate starvation $[1,19]$. APs hydrolyze phosphate ions from various organic phosphomonoesters such as glucose phosphate, lipid phosphatidates, as well as polyphosphates such as dinucleotides, trinucleotides and pyrophosphate $[16,18]$. In addition, AP dephosphorylates some proteins [14, $20,21]$, and is used as a tool to dephosphorylate termini of polynucleotides in molecular biology laboratories. Finally, AP has importance in environmental terms as an active ingredient in soil [22,23].

Enzyme inhibitors are useful as therapeutic agents and as tools for studying mechanisms of enzymatic catalysis. The potential therapeutic benefits associated with inhibition of APs would suggest value in characterizing new AP inhibitors [24]. Many different types of compounds have previously been shown to act as inhibitors for APs due to the relatively non-specific binding-pocket in these enzymes (2-3000 entries in the ChEMBL database). In addition to some inorganic ions, many

\footnotetext{
Abbreviations: pNPP, p-nitrophenyl phosphate; AP, Alkaline phosphatase; VAP, Vibrio alkaline phosphatase.

* Corresponding author.

E-mail address: bjarni@hi.is (B. Ásgeirsson).

1 ResearcherID: http://www.researcherid.com/rid/E-3747-2015.
} 
organic compounds act as non-competitive or uncompetitive inhibitors for APs, including some amino acids $[25,26]$. The diversity in the mode of action of different inhibitors is also reflective of the spatial accommodation and catalytic environment in the active site of APs, including three metal ions and a serine nucleophile that can take part in binding and partial reactions. Inorganic phosphate, being the reaction product, and ions that resemble phosphate, act reversibly as competitive inhibitors. The inhibition can also be irreversible. One example is the inhibitory effect of the bactericidal molecule imipenem on the Vibrio AP variant (VAP) under study here [27]. Several compounds have been developed as potential preventive medication for abnormal calcification and mineral depositions in humans due to hyperactivity of tissue nonspecific AP or intestinal AP. A recent example is the inhibition of human tissue nonspecific AP by tricyclic coumarin sulphonate derivatives and nicotinamide derivatives (SBI-425) where the latter has higher bioavailability [28,29].

Cyclohexylamine is a weak base, miscible with water, that is used in industries for the manufacturing of insecticides, antiseptics, and plasticizers, and is a source of environmental pollution [22]. It is also used as a counterion in some commercial preparations of the much-used non-specific phosphatase substrate $p$-nitrophenyl phosphate ( $p$ NPP). While studying the effects of other inhibitors on VAP by using higher concentrations of the common $p$-nitrophenyl phosphate substrate than previously used [30,31], we observed inhibition, that turned out to be due to the counterion in the substrate salt. What follows is a structural characterization of this inhibition by cyclohexylamine. Neither the effect of cyclohexylamine on the enzymatic activity of APs nor the crystal structure showing the binding modes have been reported before.

\section{Materials and methods}

\subsection{Materials}

Chemicals were purchased form Sigma-Aldrich (Schnelldorf, Germany) or Merck (Darmstadt, Germany) including both the disodium salt hexahydrate of $p$-nitrophenyl phosphate (4876) and 4-nitrophenyl phosphate bis(cyclohexylammonium) salt (N3129). Alkaline phosphatases from E. coli (P5931) and calf intestines (79390) were purchased from Sigma-Aldrich. Antarctic phosphatase (M0289S) was purchased from New England Biolabs. Vibrio alkaline phosphatase (VAP) was purified as previously described [32]. VAP variants were produced as previously described [33,34]. Hanging drop vapor diffusion plates (VDX24 without sealant), Polyethylene glycol (PEG) and other materials for protein crystallization were purchased from Molecular Dimensions (UK) and Hampton Research (USA).

\subsection{Activity measurements}

Enzyme activity was generally measured in $100 \mathrm{mM}$ Caps, $1 \mathrm{mM}$ $\mathrm{MgCl}_{2}$, pH 9.8 at $10^{\circ} \mathrm{C}$ over a $30 \mathrm{~s}$ period using a Peltier temperatureregulated Evolution 220 spectrophotometer (ThermoFisher). For comparative assays with other APs, kinetic measurements were performed at $25^{\circ} \mathrm{C}$. At $10^{\circ} \mathrm{C}$, the cuvettes were pre-chilled on ice to prevent fogging. Two salts of $p$-nitrophenyl phosphate ( $p N P P$ ) were used as specified, $p N P P$ bis(cyclohexylamine) or $p N P P$ disodium. The formation of $p$-nitrophenol was followed at $405 \mathrm{~nm}$ and quantified using an extinction coefficient of $18.5 \mathrm{mM}^{-1} \mathrm{~cm}^{-1}$. For exact initial substrate concentrations, the samples were fully hydrolyzed overnight, the absorbance at $405 \mathrm{~nm}$ measured and the initial concentrations calculated. Activity of VAP was also measured at $\mathrm{pH} 8.0$ in Tris buffer (100 $\mathrm{mM}$ Tris, $1 \mathrm{mM} \mathrm{MgCl}_{2}$, $\mathrm{pH}$ 8.0).

\subsection{Cyclohexylamine inhibition experiments using VAP}

Data for Lineweaver-Burk plots were obtained either at pH 9.8 (100 mM Caps, $1 \mathrm{mM} \mathrm{MgCl}_{2}$ ) or at $\mathrm{pH} 8.0\left(100 \mathrm{mM}\right.$ Tris, $\left.1 \mathrm{mM} \mathrm{MgCl}_{2}\right)$ with temperature regulated at $10{ }^{\circ} \mathrm{C}$. At $\mathrm{pH} 9.8, \mathrm{pNPP}$ disodium at $0.0-1.0$ $\mathrm{mM}$ was used as a substrate and cyclohexylamine was added from a 1.73 M stock solution prepared by diluting pure cyclohexylamine 1:4 water and pre-adjusting the $\mathrm{pH}$ to the assay conditions with $6.0 \mathrm{M} \mathrm{HCl}$ ). Cyclohexylamine was included in the assay medium at the appropriate concentration. GraphPad Prism ${ }^{\circledR}$ was used to analyze the data as a noncompetitive inhibition. The inhibition mechanism was also evaluated using a mixed inhibition model, where the data was fitted globally in Graphpad Prism to the equation:

$$
\mathrm{v}=\frac{V_{\max } *[S]}{[S]\left(1+\frac{[l]}{\alpha K_{i}}\right)+K_{M}\left(1+\frac{[l]}{K_{i}}\right)}
$$

If the $\alpha$ constant $=1$, the inhibition is non-competitive in nature. Then, the inhibitor displays equal affinity for both the free enzyme and the ES complex. If $\alpha<1$, then the inhibitor binds with greater affinity to the ES complex than the free enzyme (uncompetitive inhibition). If $\alpha>$ 1 , then the inhibitor prefers binding to the free enzyme (uncompetitive inhibition) [35].

For evaluation of the inhibitor's potency, standard enzyme activity was measured in the presence of increasing cyclohexylamine concentration, ranging from 0 to $400 \mathrm{mM}$, with a constant $2 \mathrm{mM} p \mathrm{NPP}$ disodium concentration. At $\mathrm{pH} 9.8,0.5 \mathrm{M} \mathrm{NaCl}$ was added to the buffers to counteract ionic activation of the enzyme (due to titration of cyclohexylamine with $\mathrm{HCl}$ ) which plateaus at $0.5 \mathrm{M}$. At pH 8.0, the activity of the enzyme is even more dependent on ionic strength (activity plateaus when $\mathrm{NaCl}$ is above $1.0 \mathrm{M}$ ). Therefore, the activation due to ionic strength (chloride) was corrected at $\mathrm{pH} 8.0$ using the equation:

$\mathrm{v}_{\text {corrected }}=\mathrm{v}_{\text {app }} /(1+4.010 * \mathrm{x} /(0.2169+\mathrm{x}))$

where $\mathrm{v}_{\text {corrected }}$ is the corrected activity, $\mathrm{v}_{\text {app }}$ the obtained activity, and $\mathrm{x}$ is the concentration of chloride. This equation is derived from a hyperbolic fit measured previously under identical conditions with various concentration of $\mathrm{NaCl}$ [36].

A relative $\mathrm{IC}_{50}$ value was determined at $50 \%$ of the maximum inhibition [37]. We obtained $\mathrm{K}_{\mathrm{i}}$-values using the relationship $\mathrm{K}_{\mathrm{i}}=\mathrm{IC}_{50}$ that holds for non-competitive inhibition [38].

For evaluation of reversibility of inhibition, enzyme samples were incubated with $50 \mathrm{mM}$ cyclohexylamine for $10 \mathrm{~min}$ on ice in $100 \mathrm{mM}$ Caps at pH 9.8 with $1 \mathrm{mM} \mathrm{MgCl}_{2}$ and $0.5 \mathrm{M} \mathrm{NaCl}$ added. Enzyme activity was then measured with or without cyclohexylamine $(50 \mathrm{mM})$ added to the Caps reaction buffer containing $2 \mathrm{mM} p$ NPP disodium. Ten $\mu \mathrm{l}$ of enzyme were added to $990 \mu \mathrm{L}$ of reaction buffer to initiate the enzyme reaction, effectively diluting the inhibitor concentration from 50 to 0.5 $\mathrm{mM}$ as a carry-over in the control. This concentration would be too low to affect enzyme activity.

\subsection{X-ray crystallography}

A Phoenix crystallization robot (Art Robbins Instruments) was used to screen for crystallization conditions by the sitting drop vapor diffusion method. Crystallization conditions containing NaCl and PEG3350 and buffered around neutral $\mathrm{pH}$ were designed using FORMULATRIX®. The initial screen gave three hits, which were fully optimized before attempting co-crystallization with cyclohexylamine.

In order to produce cyclohexylamine bound VAP crystals, a $15 \mathrm{mg} /$ mL VAP solution was mixed with $2.0 \mathrm{M}$ cyclohexylamine (pre-titrated to $\mathrm{pH} 8.0$ ) to a final concentration of $10 \mathrm{mg} / \mathrm{mL}$, the final ligand concentration being $200 \mathrm{mM}$ (around 5-fold $\mathrm{K}_{\mathrm{m}}$ ). The solution was left on ice for an hour before use in co-crystallization experiments to allow for sufficient ligand binding. Original crystallization experiments proved to be unsuccessful due to the increased solubility of the protein upon addition of the ligand solution. The lack of nucleation was addressed by micro-seeding. The ligand bound VAP crystals were grown under $0.5 \mathrm{M}$ $\mathrm{NaCl}, 22 \%(\mathrm{w} / \mathrm{v})$ PEG3350 and $0.1 \mathrm{M}$ Tris $\mathrm{pH} 7.0$ in $2 \mu \mathrm{L}$ drops 
consisting of $1.5 \mu \mathrm{L}$ enzyme/ligand solution, 0.5 micro-seed (1000x dilution) and $1.5 \mu \mathrm{L}$ reservoir solution, seated over a $500 \mu \mathrm{L}$ reservoir using the hanging-drop vapor diffusion method. In order to produce the seeds, VAP crystals grown under similar conditions $(0.7 \mathrm{M} \mathrm{NaCl}, 20 \%$ $(\mathrm{w} / \mathrm{v})$ PEG3350 and $0.1 \mathrm{M}$ Tris $\mathrm{pH}$ 7.0), were crushed while in the original crystallization drop and diluted 1000 -fold in the mother liquor. A single, triangular crystal with approximate dimension of $130 \times 50 \times$ $20 \mu^{3}$ was harvested after a three day incubation period at $298 \mathrm{~K}$, submerged in cryo-protecting oil (LV CryoOil, MiTeGen, Ithaca, NY) and frozen in liquid $\mathrm{N}_{2}$. The crystal diffracted to $2.26 \AA$ (Table 1) and allowed for model building and identification of two distinct cyclohexylamine binding sites.

X-ray diffraction data were collected at the BioMAX beamline at the MaxIV laboratory (Lund, Sweden). Data were processed and scaled using XDS [39] and AIMLESS [40]. Phases were solved with molecular replacement using PHASER within the Phenix interface [41,42], using

Table 1

VAP co-crystallized with cyclohexylamine. Data collection, refinement and validation statistics. Statistics for the highest resolution shell are shown in parenthesis.

\begin{tabular}{|c|c|}
\hline \multicolumn{2}{|l|}{ Data collection } \\
\hline Wavelength (energy) & $0.9184 \AA$ (13.5 keV) \\
\hline Space group & $\mathrm{P} 22_{1}$ \\
\hline Unit cell parameters & $\begin{array}{l}\mathrm{a}=76.92 \AA, \mathrm{b}=85.27 \AA, \mathrm{c}=84.79 \AA \\
\alpha=\beta=90.0^{\circ}, \gamma=113.5^{\circ}\end{array}$ \\
\hline Resolution range & $29.43-2.26(2.38-2.26)$ \\
\hline Observed reflections & 345308 (19763) \\
\hline Unique reflections & $50781(3040)$ \\
\hline Multiplicity & $6.8(6.5)$ \\
\hline Completeness (\%) & $99.0(94.5)$ \\
\hline Mean $I / \sigma(I)$ & $13.0(2.5)$ \\
\hline Wilson B-factor & 37.78 \\
\hline $\mathrm{R}_{\text {merge }}(\%)^{\mathrm{a}}$ & $9.4(67.1)$ \\
\hline \multicolumn{2}{|l|}{ Refinement } \\
\hline Reflections used in refinement & $46417(4301)$ \\
\hline $\mathrm{R}_{\text {work }} \mathrm{b}$ & $0.160(0.198)$ \\
\hline$R_{\text {free }}{ }^{c}$ & $0.205(0.253)$ \\
\hline RMSD (bonds) & 0.003 \\
\hline RMSD (angles) & 0.58 \\
\hline \multicolumn{2}{|l|}{ Asymmetric unit contents } \\
\hline Non-hydrogen atoms & 8297 \\
\hline Macromolecules & 7834 \\
\hline Ligands & 28 \\
\hline Solvent & 411 \\
\hline Protein residues & 1004 \\
\hline \multicolumn{2}{|l|}{ Average B-factors $\left(\AA^{2}\right)$} \\
\hline All atoms & 40.65 \\
\hline Macromolecules & 40.61 \\
\hline Ligands & 41.56 \\
\hline Solvent & 41.40 \\
\hline \multicolumn{2}{|l|}{ Validation } \\
\hline $\begin{array}{l}\text { Ramachandran favored/allowed/outliers } \\
\text { (\%) }\end{array}$ & $98.10 / 1.90 / 0.00$ \\
\hline Rotamer outliers (\%) & 0.36 \\
\hline $\mathrm{C} \beta$ outliers & 0 \\
\hline Clash score & 2.82 \\
\hline MolProbity score & 1.07 (100th percentile ${ }^{\mathrm{d}}$ ) \\
\hline PDB code & $6 \mathrm{~T} 26$ \\
\hline \multicolumn{2}{|c|}{$\begin{array}{l}\text { reflection } h k l \text { and }\langle I(h k l)><I(h k l)>\text { is the weighted average intensity for al } \\
\text { observations of reflection } h k l \text {. } \\
\text { b } R_{\text {work }}=\Sigma\left|F_{\text {obs }}-F_{\text {calc }}\right| \Sigma F_{o b s} \text {, where } F_{\text {obs }} \text { and } F_{\text {calc }} \text { are observed and calculated } \\
\text { reflections, respectively. } \\
\text { c } R_{\text {free value was calculated as } \mathrm{R}_{\text {work }} \text {, using only an unrefined, randomly }} \text { chosen subset of reflection data }(4.35 \%) \text { that were excluded from refinement. } \\
\text { d For structures of comparable resolution ( } \mathrm{N}=8894,2.265 \AA \pm 0.25 \AA \text { ). }\end{array}$} \\
\hline
\end{tabular}

the previously solved crystal structure of native VAP (PDB: 3E2D) [31] as the reference model. Refinement was carried out in PHENIX.REFINE [43], and manual model building performed in Coot [44]. The final, refined structure was validated using MolProbity [45] and the data was analyzed in Xtriage (Phenix) [42]. Simulated annealing (SA) Fo-Fc omit map for bound ligands were calculated in Phenix and images of the models were drawn in PyMOL [46]. Data collection, refinement and validation statistics can be seen in Table 1 .

\section{Results}

\subsection{Cyclohexylamine is a non-competitive inhibitor of VAP}

Fig. 1a shows the concentration dependence of $p$-nitrophenyl phosphate ( $p N P P$ ) hydrolysis at $\mathrm{pH} 9.8$, which is the $\mathrm{pH}$ optimum of the enzyme, either using the disodium salt or the bis(cyclohexylamine) salt. Inhibition was observed at substrate concentrations above $1 \mathrm{mM}$ using the bis(cyclohexylamine) salt, but was not observed with the disodium salt. This suggested that the inhibitory effect was due to the cyclohexylamine counterion. The inhibition at $\mathrm{pH} 9.8$ remained unchanged by adding $0.5 \mathrm{M} \mathrm{NaCl}$ (Fig. 1a).

At pH 8.0 (Fig. 1b), enzyme activity was more effectively inhibited by cyclohexylamine without added $\mathrm{NaCl}$, being reduced to ca. $25 \%$ of the calculated maximum activity at $6 \mathrm{mM} p \mathrm{NPP}$ (equivalent to $12 \mathrm{mM}$ cyclohexylamine). The addition of $0.5 \mathrm{M} \mathrm{NaCl}$ alleviated the inhibition to the level observed at $\mathrm{pH} 9.8$, where no effect of salt was observed (Fig. 1a).

To confirm that inhibition was due to cyclohexylamine, we also prepared the stock solution of disodium $p$ NPP with 2 M equivalents of cyclohexylamine added, before serial dilution (Fig. 1c). The results were practically identical, indicating that cyclohexylamine is the inhibitory molecule, rather than a contaminating species. Furthermore, using two different batches of bis(cyclohexylamine) pNPP gave identical inhibitory results (data not shown).

Fig. 2 shows additional experiments using $p$-nitrophenyl phosphate disodium as substrate that confirms cyclohexylamine as a noncompetitive inhibitor of VAP. A Lineweaver-Burk plot of VAP activity at $\mathrm{pH} 9.8$ (Fig. 2b) made from the progress curves (2a) showed a decrease in $\mathrm{V}_{\max }$ with increasing inhibitor concentration with the regression lines intercepting the $\mathrm{x}$-axis in one point. The unchanged $\mathrm{K}_{\mathrm{m}}$ value indicated a non-competitive inhibition. The $\mathrm{K}_{\mathrm{m}}$ of $195 \pm 4 \mu \mathrm{M}$ (n $=3$ ) obtained here compared well with the previously published value of $194 \pm 30 \mu \mathrm{M}$ [32]. At pH 8.0, the lines intercepted the $\mathrm{x}$-axis slightly above the $y$-axis, which could indicate a change in conformation of the enzyme in either the ES or ESI states at $\mathrm{pH} 8.0$ compared to $\mathrm{pH} 9.8$ (Fig. 2d), making the inhibitor binding site non-equivalent to the substrate binding-site. We also tested a mixed model inhibitor analysis that gives the factor $\alpha$ as the ratio of the equilibrium constant for EI formation $\left(\mathrm{K}_{i}\right)$ and for ESI formation $\left(\alpha \mathrm{K}_{\mathrm{i}}\right)$. The $\alpha$-factor was 1.4 and 1.2 for $\mathrm{pH} 8.0$ and 9.8, respectively, indicating a mostly non-competitive type of interaction (Fig. 2a and c).

When $\mathrm{V}_{\max }$ as determined at $\mathrm{pH} 9.8$ was plotted against enzyme concentration (Fig. 2e), either measured with a substrate solution containing $50 \mathrm{mM}$ cyclohexylamine, or without the inhibitor, the lines intersected at the origin, which is consistent with a non-competitive inhibition [47]. The inhibition was immediately reversible upon dilution.

Fig. 3a shows the activity of VAP when measured with a constant $p$ NPP disodium concentration $(2 \mathrm{mM})$ in the presence of increasing concentrations of cyclohexylamine up to $400 \mathrm{mM}$ at $\mathrm{pH} 9.8$. From Fig. $3 \mathrm{a}$, the $\mathrm{IC}_{50}$ value was $35.7 \mathrm{mM}$ at $50 \%$ of the maximum inhibition obtained here (14\% residual activity being still left) [37] and $45.3 \mathrm{mM}$ if the scaling of inhibition was taken from zero. As mentioned above, the relationship $\mathrm{K}_{\mathrm{i}}=\mathrm{IC}_{50}$ [38] holds for non-competitive inhibition.

A considerable amount of chloride accompanies the necessary pretitration of cyclohexylamine with $\mathrm{HCl}$ in order to maintain the correct 

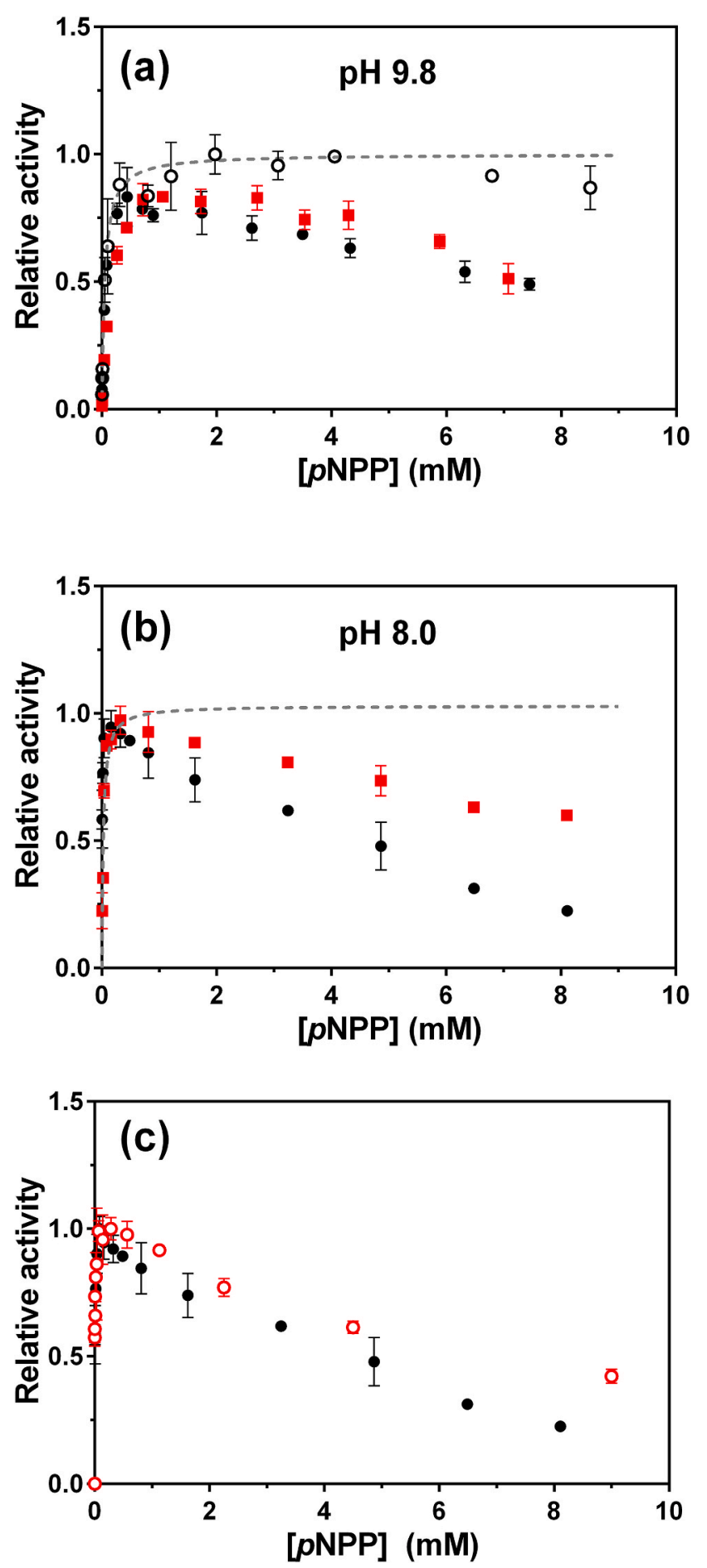

Fig. 1. VAP activity with two different $p$-nitrophenyl phosphate salts as a substrate. (a) VAP activity was assayed either with the disodium (open circles) or the cyclohexylamine (closed symbols) salts of p-nitrophenyl phosphate (pNPP) at $\mathrm{pH} 9.8$ without added $\mathrm{NaCl}$ (closed circles) and with the addition of $0.5 \mathrm{M} \mathrm{NaCl}$ (red closed squares). (b) Same conditions with same data denotation as in (a) but measured at $\mathrm{pH}$ 8.0. (c) The result of adding $2 \mathrm{~mol}$ of cyclohexylamine to each mole of disodium pNPP (open circles) compared with results obtained with cyclohexylamine salt of pNPP alone at the same concentration of pNPP. The figure shows results from a representative experiment performed in triplicate. The effective concentration of cyclohexylamine was twice that presented in the figures due to bis-form of the pNPP-salt. The dotted line is a calculated fit to the Michaelis-Menten equation using the apparent $\mathrm{K}_{\mathrm{m}}$ calculated for the concentration range $0-0.5 \mathrm{mM}$ in each case. (For interpretation of the references to color in this figure legend, the reader is referred to the Web version of this article.)
$\mathrm{pH}$ in all samples. Previous results have shown that the activation of VAP caused by ionic strength is specific for the anion and plateaus at around $0.5 \mathrm{M}$ at $\mathrm{pH} 9.8$, but goes above $1.0 \mathrm{M}$ at $\mathrm{pH} 8.0$ [36]. This causes a complication, since a considerable amount of chloride is added with the cyclohexylamine (roughly equimolar in concentration). Thus, the chloride and the inhibitor have an opposing effect on the enzyme activity (through independent mechanisms), complicating the determination of inhibitor binding potency. We could approximate the activation by chloride and correct for the anionic activation at $\mathrm{pH} 8.0$ using eq. (2) shown in Materials and methods. Using this approximation, we derived a similar result as in Fig. 3a with slightly lower $\mathrm{IC}_{50}$ value of $27.9 \mathrm{mM}$ at $50 \%$ of the maximum inhibition (i.e. $20 \%$ residual activity). The addition of $0.5 \mathrm{M} \mathrm{NaCl}$ was shown (Fig. 3b) to decrease the potency of the inhibitor resulting in an increase in $\mathrm{IC}_{50}$ to $46.7 \mathrm{mM}$ at $50 \%$ of the maximum inhibition obtained (i.e. $15 \%$ residual activity).

\subsection{Structural details of cyclohexylamine binding to VAP by $x$-ray crystallography}

The VAP-CHA complex crystallized in the primitive $\mathrm{P} 2{ }_{1}$ space group, and the asymmetric unit of the crystal consisted of a single VAP dimer (Table 1; Fig. 4). The enzyme contained the reaction product, inorganic phosphate $\left(\mathrm{P}_{\mathrm{i}}\right)$, bound in both active sites as the non-covalent enzyme product $(\mathrm{E} \bullet \mathrm{P})$ intermediate. $\mathrm{P}_{\mathrm{i}}$ was not present in the crystallization medium and must, therefore, have remained bound to the enzyme through expression and purification. The cyclohexylamine bound to VAP in two distinctive sites on each subunit, one in proximity of the substrate binding site, and the other close to the dimer interface. The overall structure of the enzyme was similar to the previously solved crystal structure of VAP (PDB: 3E2D) [31], with a $\mathrm{C}_{\alpha}$-RMSD of $0.407 \AA$ and identical active site metal coordination. However, two magnesium ions, not observed in the original crystal structure, were found bound to each subunit in the new crystal structure. One was bound on the dimer interface of the protein (depicted green in Fig. 4), forming a bridge between the two subunits, and the other was bound on the edge of the central $\alpha / \beta$-domain (depicted red in Fig. 4). Both ions were pentacoordinated in a trigonal bipyramid geometry and are identically positioned to the additional magnesium ions found in the highly homologous Halomonas sp. alkaline phosphatase [48]. The buried solvent accessible surface area at the dimer interface was increased compared to the previously solved wild-type crystal structure. The number of hydrogen bonds increased from 54 to 61, whereas the number of salt bridges remained the same, being four in both structures.

Fig. $5 \mathrm{a}$ and $\mathrm{b}$ detail the binding position of cyclohexylamine with $\mathrm{a}$ protonated amine group in the active site of VAP's two subunits, whereas $5 \mathrm{c}$ is a schematic made in LigPlot with maximum donor and acceptor hydrogen bond distances set at $3.5 \AA$. A charge-charge interaction was formed by cyclohexylamine with the inorganic phosphate. Further hydrogen bonds extended from the positive charge of cyclohexylamine through water connecting with His116, Arg129, and Tyr441. Additional binding came from hydrophobic packing against Trp274 and His277. Fig. 5a and b also show the pivotal Arg129 that has a major role in binding the phosphate ligand in all APs, and may modulate its binding affinity by structural fluctuations. Interestingly, a hydrogen bonding interaction through water to Tyr325 in the other subunit was noted. Fig. 5d shows how the cyclohexylamine filled the entrance tunnel to the binding site of inorganic phosphate in VAP, and thereby, might retard product release, but also allow the binding of the organic part of the substrate alongside. The binding of the ligand in both active sites was confirmed by the SA Fo-Fc omit map (Fig. 5a and b). Interestingly, the observed occupancy of the ligand seemed to be higher in subunit B, resulting in disruption of the active site hydrogen bonding network and displacement of Tyr423.

Fig. 6 illustrates the peripheral binding position of cyclohexylamine on the surface near the dimer interface located around $20 \AA$ from the nucleophilic Ser65. The $C$-terminal of the protein folds to form two 

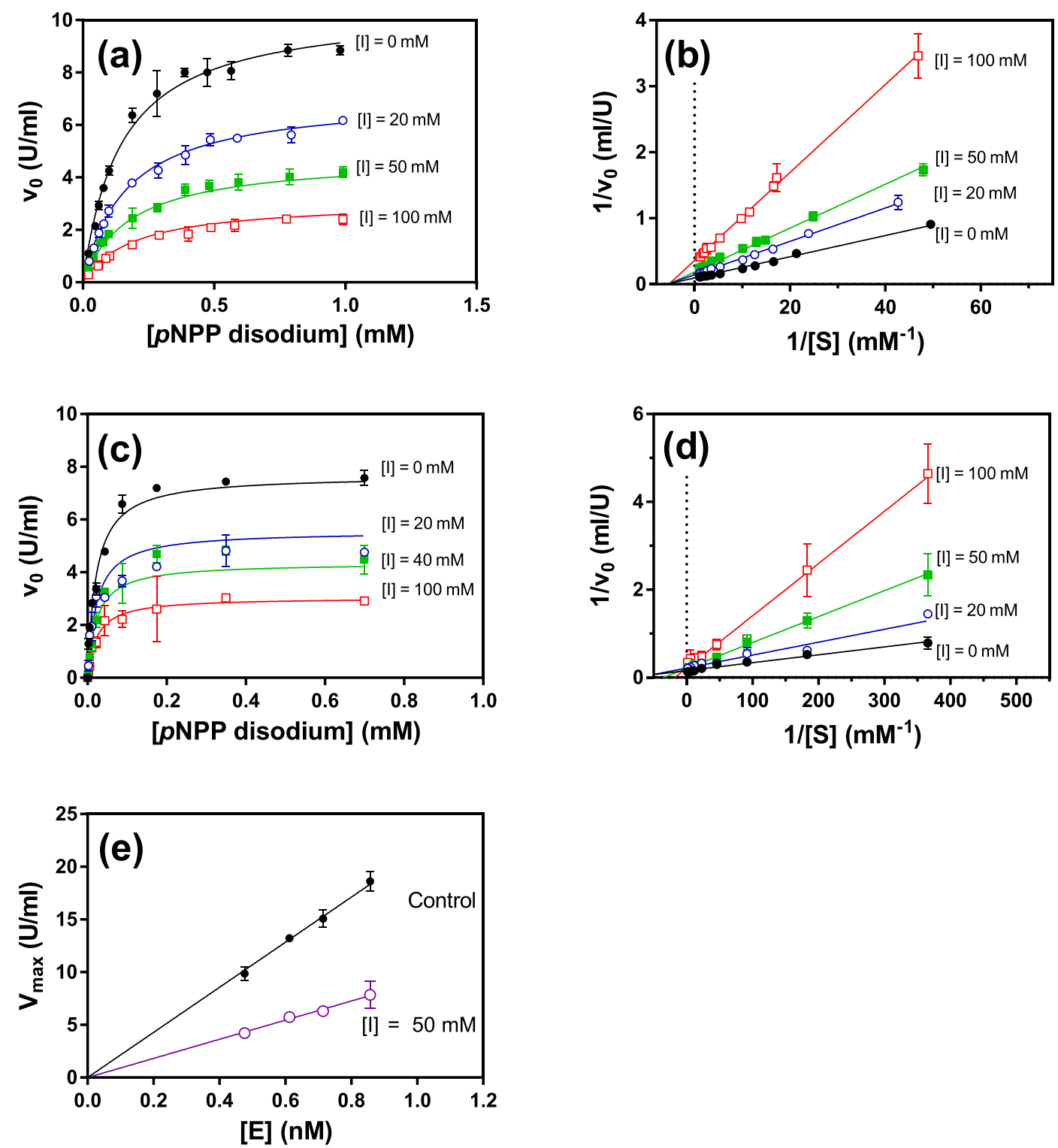

Fig. 2. The effect of $\mathrm{pH}$ on the type of inhibition of VAP by cyclohexylamine. (a) VAP activity was measured with disodium $p \mathrm{NPP}$ at $\mathrm{pH} 9.8$ (a, b) and $\mathrm{pH} 8.0$ (c, d) with varying concentrations of cyclohexylamine as shown. Global mixed inhibition analysis (a, c) and Lineweaver-Burk reciprocal analysis (b, d) were performed to evaluate type of inhibition. (e) $\mathrm{V}_{\max }$ is plotted as a function of enzyme concentration without cyclohexylamine (black circles) or with $50 \mathrm{mM}$ inhibitor (black squares) using $2 \mathrm{mM} p \mathrm{NPP}$ disodium as substrate. $\mathrm{n}=3$ from a representative experiment.

$\alpha$-helices (number 24 and 26 in the sequence) and an interconnecting $\gamma$-turn preceding a short $\beta$-strand (number 25 in sequence). Overall, residues 483-496 of this motif constitute the binding site. The binding was symmetrical in both subunits and the ligand was bound via hydrophobic packing against Pro483, Val484, Lys486, Met488, Glu492 and Tyr496. A chloride ion bound to Lys486 was positioned $3.9 \AA$ from the ligand's ammonium group, further contributing to binding (Fig. 6a). It was $6.9 \AA$ away to the newfound dimer interface magnesium ion (Fig. 6b). Fig. 6c shows that the interactions were to a great extent hydrophobic in nature.

\subsection{Effect of cyclohexylamine on other APs and variants of VAP}

The inhibitory effect of cyclohexylamine on three other APs, from E. coli, calf intestines and an Antarctic bacterium (TAB5), was also tested. The two cold-active APs were similarly inhibited by cyclohexylamine, whereas the enzymes from $E$. coli (ECAP) or calf intestines were less sensitive to the inhibitory effect (Fig. 3). VAP and TAB5 from an
Antarctic bacterium [49] are both members of the AP subfamily with a Trp in the position numbered 274 in VAP, instead of His (in mammalian APs) or Lys 328 in ECAP. As Fig. 3 shows, the cold-active APs were more sensitive to inhibition by cyclohexylamine compared with the more heat-tolerant variants. Fig. 5 showed how cyclohexylamine forms primary interactions with Trp274 in VAP. Therefore, we decided to test the binding of cyclohexylamine to VAP variants, where Trp274 was exchanged for a neutral alanine or a positively charged residue, either histidine or lysine. A positive charge would be expected to reduce binding affinity for the positively charged ligand. The $\mathrm{IC}_{50}$ (the concentration needed to reduce the initial activity by one half, but leaving about $20 \%$ in residual activity in all cases) was $179 \pm 27(\mathrm{n}=5)$ with W274A, $188 \pm 26 \mathrm{mM}(\mathrm{n}=6)$ with W274K and $187 \pm 10 \mathrm{mM}(\mathrm{n}=3)$ with W274H. Compared with the wild-type value of $45.3 \mathrm{mM}$, all these values are considerably higher, indicating lower binding affinity. 

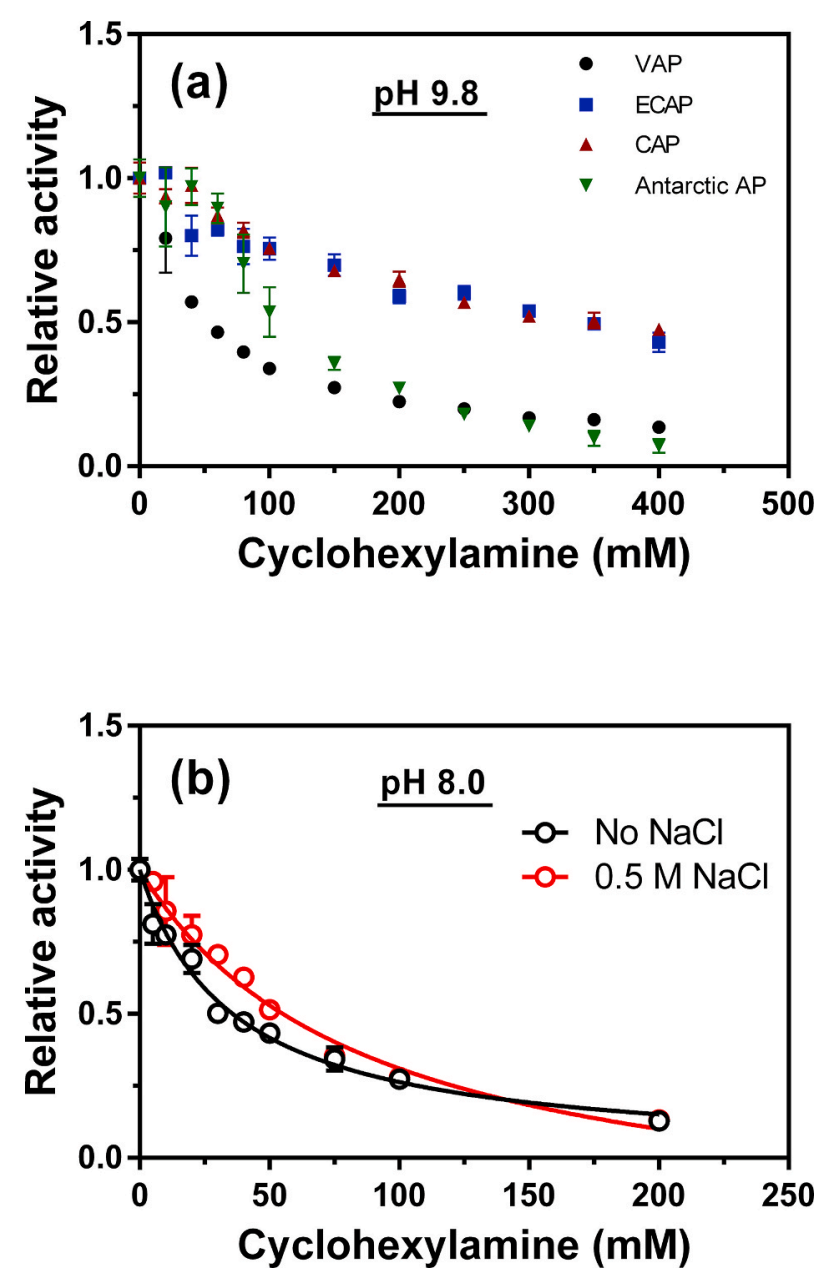

Fig. 3. The effect of cyclohexylamine on APs from different organisms. (a) Activity was measured with $2 \mathrm{mM}$-nitrophenyl phosphate disodium at $\mathrm{pH} 9.8$ and $25{ }^{\circ} \mathrm{C}$ in a $100 \mathrm{mM}$ CAPS buffer containing $500 \mathrm{mM} \mathrm{NaCl}$. For VAP, a $\mathrm{K}_{\mathrm{i}}$ value of $45.3 \mathrm{mM}$ and a maximum inhibition of $86 \%$ was observed. VAP (circles); TAB5 AP (triangle pointing down); E. coli AP (rectangle) and calf intestinal AP (triangle pointing up). (b) VAP was measured in a similar way as in (a), but at $\mathrm{pH} 8.0$ in a $100 \mathrm{mM}$ Tris buffer, with and without the addition of NaCl. $\mathrm{n}$ $=3$ from a representative experiment.

\section{Discussion}

\subsection{Inhibitory effects of cyclohexylamine}

The inhibition of an alkaline phosphatase by cyclohexylamine has not been previously reported. When VAP activity was tested using $p$ NPP disodium, no inhibition was observed, confirming that the inhibition was due to cyclohexylamine. Both the $\mathrm{k}_{\text {cat }}$ and $\mathrm{K}_{\mathrm{m}}$ of VAP are very $\mathrm{pH}$ dependent over the range compared here $(\mathrm{pH} 8.0$ and $\mathrm{pH} 9.8)$. At $\mathrm{pH}$ 8.0 , the $p$ NPP substrate is fully negatively ionized $\left(\mathrm{pK}_{2}=5.60[1]\right)$ and the cyclohexylamine fully protonated. At $\mathrm{pH} 9.8$, the cyclohexylamine should be $85 \%$ protonated. Thus, the difference observed in the extent of the inhibition at $\mathrm{pH} 8.0\left(\mathrm{~K}_{\mathrm{i}}=27.9 \mathrm{mM}\right)$ compared with $\mathrm{pH} 9.8\left(\mathrm{~K}_{\mathrm{i}}=\right.$ $35.7 \mathrm{mM}$ ) must have its root in changing properties of the enzyme, involving changes in the charge-state of binding residues, and/or conformational shifts with effects on geometry and electrostatic fields.

Cyclohexylamine is a weak base $\left(\mathrm{pK}_{\mathrm{a}}=10.63\right)$ and it was necessary to pre-titrate the inhibitor to the assay's $\mathrm{pH}$ with $\mathrm{HCl}$ prior to use in order to maintain constant $\mathrm{pH}$. This added about $95 \%$ of the inhibitor's molarity in chloride ions. Previous studies have shown that $\mathrm{NaCl}$ has a stabilizing effect on the enzyme structure and facilitates catalysis [36]. This presented some experimental complications to using activity as a measure of the inhibitor binding efficacy. As the salt effect on VAP has been shown to peak at $0.5 \mathrm{M} \mathrm{NaCl}$ at $\mathrm{pH} 9.8$ [36], this concentration was added to the buffers to cancel out the effect of the salt brought in by low amount of cyclohexylamine on kinetic measurements (Fig. 1). At pH 8.0, however, the salt is effective beyond $1 \mathrm{M} \mathrm{NaCl}$ in increasing $\mathrm{k}_{\text {cat }}$. We approximated the effect of chloride in that case by a correction constant derived from previous observation for chloride activation under same assay conditions [36]. This correction method could have caused the slight deviation seen from pure non-competitive inhibition in Fig. $2 \mathrm{~b}$ and $\mathrm{d}$. By adding salt, we shifted the inhibition at $\mathrm{pH} 8.0$ to values comparable to those at $\mathrm{pH} 9.8$, but adding salt did not affect the concentration dependence $\left(\mathrm{K}_{\mathrm{m}}\right)$ at $\mathrm{pH} 9.8$ much. The fact that a total of 900 $\mathrm{mM}$ of chloride ions was present when $400 \mathrm{mM}$ cyclohexylamine was tested in the presence of $500 \mathrm{mM} \mathrm{NaCl}$ may offer an explanation as to why cyclohexylamine maximally produced $86 \%$ inhibition (Fig. 3). Since the cyclohexylamine is largely protonated under the test conditions, the $\mathrm{NaCl}$ could be interfering with ionic interactions between the inhibitor and the enzyme. One might speculate with reference to a half-of-site reaction mechanism [50] that there are two populations of enzyme molecules and the inhibitor only binds strongly to one of the two subunits at a time, and cannot fully prevent the other active site from catalyzing the reaction. Another suggestion would be that the EI (or ESI) form of the enzyme was not fully inactive, but promoted catalysis at a much reduced turnover rate.

\subsection{X-ray crystal structure of cyclohexylamine bound to VAP}

APs are sensitive to inhibition by compounds of various structures, the most potent inhibitors being effective in the sub-micromolar range [51]. The structure of VAP in the co-crystal state reported here was almost identical to the previously solved wild-type structure (PDB: 3E2D), with a $C_{\alpha}$ RMSD of $0.407 \AA$. The sulfate anion present in the earlier VAP crystal from the crystallization medium was replaced by an inorganic phosphate ion in the present case. Some of the rotamers observed for active site residues were not identical in the two subunits, and/or deviated from that of the previously published crystal structure for wild-type VAP. Tyr423 took on two rotameric forms in subunit B, where the occupancy of the ligand seemed higher compared to subunit A that showed only one rotamer (Fig. 5a and b). Presumably, this was due to rearrangements in the active site hydrogen bonding network of each monomer, caused by the binding of the inhibitor. By comparison with the earlier wild-type crystal structure, where the nucleophilic Ser65 took on two rotamer positions, only one rotamer was observed here (Fig. 5). Presumably, this rotamer corresponds to the protonated form of the nucleophile which is bound via hydrogen bonding to one of the magnesium coordinating water molecules, and the magnesium coordinating Thr118 and Asp12.

Cyclohexylamine was bound to VAP in direct coordination with the reaction product which is inorganic phosphate (Fig. 5), and it was also found bound close to the dimer interface (Fig. 6). The active site ligand binding was in large part coordinated through charge-charge interactions between the ammonium cation of the inhibitor and the bound reaction product $\left(\mathrm{P}_{\mathrm{i}}\right)$. The protonation state of both $\mathrm{P}_{\mathrm{i}}$ and cyclohexylamine cannot be confirmed, but the phosphate is likely fully deprotonated as a result of the numerous surrounding cations. Decreased inhibition at the higher $\mathrm{pH}$ of 9.8 in comparison to $\mathrm{pH} 8.0$ was likely due to the lessened protonation of cyclohexylamine and a loss of the positive charge interacting with a fully anionic $\mathrm{P}_{\mathrm{i}}$. The decreased inhibition at $\mathrm{pH}$ 9.8 could likewise occur as a result of decreased affinity of the alkaline conformer towards the inhibitor due to conformational changes that VAP is thought to undergo at alkaline $\mathrm{pH}$ [36].

In non-competitive inhibition, it is generally assumed that in order for the enzyme-inhibitor complex to form, the inhibitor must bind at a site other than the active site [52]. Therefore, finding the non-competitive inhibitor bound close to where the phosphate binds in the active site of the enzyme was quite surprising. Active site binding of 


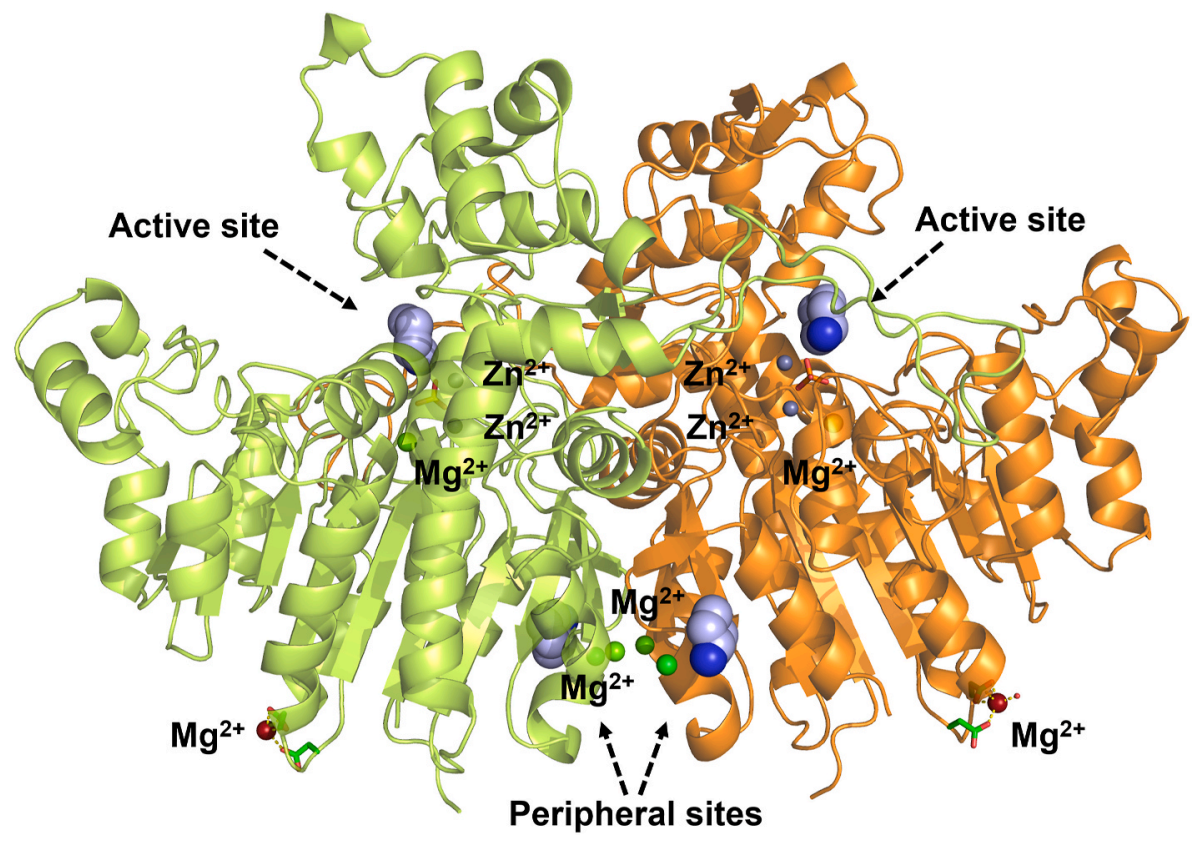

Fig. 4. VAP co-crystallized with cyclohexylamine shows two binding sites per subunit in the overall structure. The asymmetric unit of the crystal was a single VAP dimer with four cyclohexylamine molecules bound shown as blue space-filling models and the two subunits in olive ands orange, respectively. The zinc ions are shown as grey spheres and magnesium ions in the active sites and at the interface as dark green spheres. The phosphate ion bound in the active sites of the enzyme is shown as red and orange sticks. Additionally, the magnesium ion found at the surface is shown in red with ligands (For interpretation of the references to color in this figure legend, the reader is referred to the Web version of this article). (a)

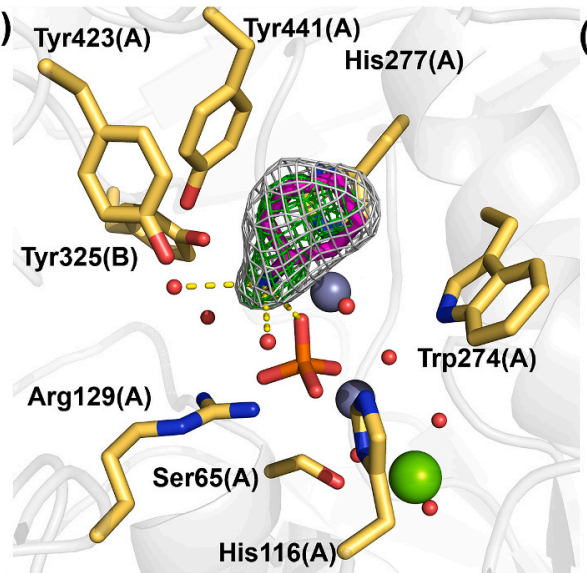

(c)

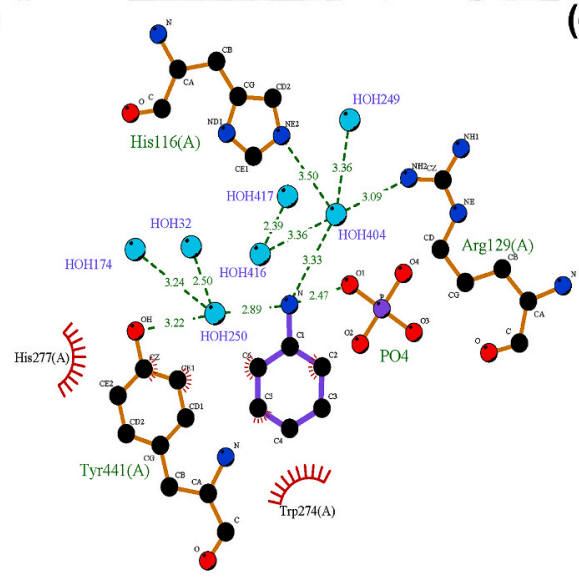

(b)

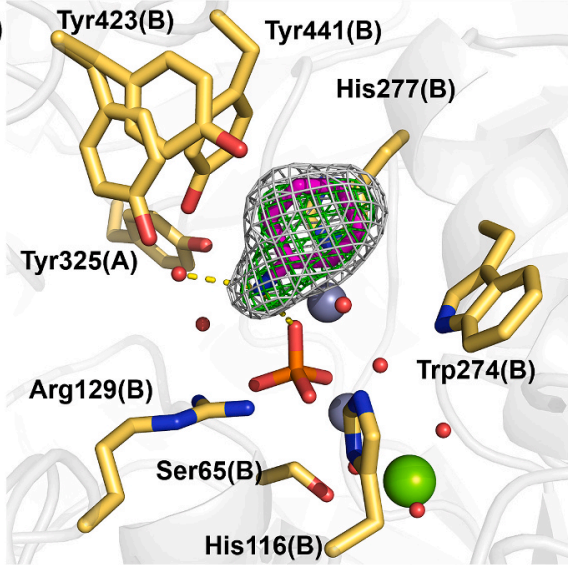

(d)

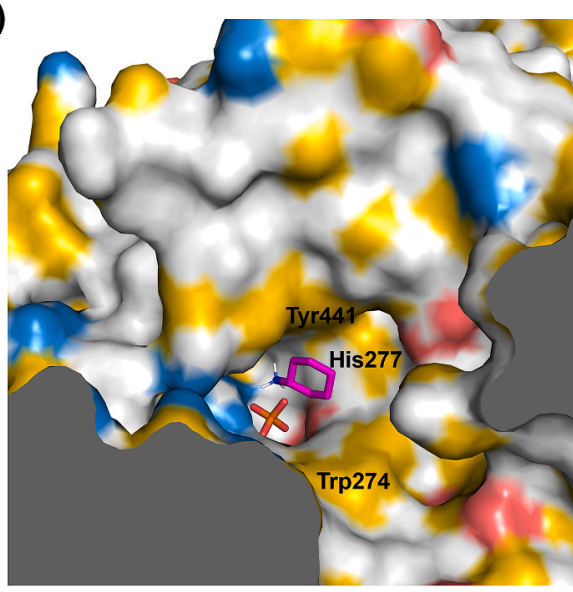

Fig. 5. Binding of cyclohexylamine in the active sites of the two VAP subunits. (a) The binding of the ligand in the active site of monomer A, and (b) in monomer B, with polar contacts $(<3.5 \AA)$ shown as yellow dashes. The cyclohexylamine is shown as magenta and blue sticks, water molecules forming polar contacts with the ligand are shown as red spheres and inorganic phosphate as yellow and orange sticks. The active site magnesium ion is colored as a green sphere and the two zinc ions as grey spheres. The final refined $2 \mathrm{~F}_{\mathrm{o}}-\mathrm{F}_{\mathrm{c}}$ map (grey) is contoured at $1 \sigma$ and the SA Fo-Fc omit map (green) at 5.5б. (c) A ligand plot drawn using LigPlot [65] further illustrating the binding in monomer $\mathrm{A}$ to acceptors/donors within $3.5 \AA$. (d) A view of the substrate entry channel of the active site, showing inorganic phosphate being eclipsed by the bound cyclohexylamine. The sliced surface is colored according to the YRB coloring scheme [66] (For interpretation of the references to color in this figure legend, the reader is referred to the Web version of this article). non-competitive inhibitors can occur in the context of an isomechanism of catalysis. An isomechanism refers to a mechanism where the enzyme binds the substrate in one conformational state but releases the product in another, and to reinitiate catalysis it must converge back to the substrate binding form upon product release. In isomechanismic [53] enzymes, binding of the inhibitor in the active site of the product releasing conformer does not directly compete with the substrate for binding and can result in non-competitive inhibition [54,55]. APs catalyze the hydrolysis of phosphomonoesters via a bi-bi ping-pong mechanism (Scheme 1). We have indicated two structural forms of VAP 
(a)
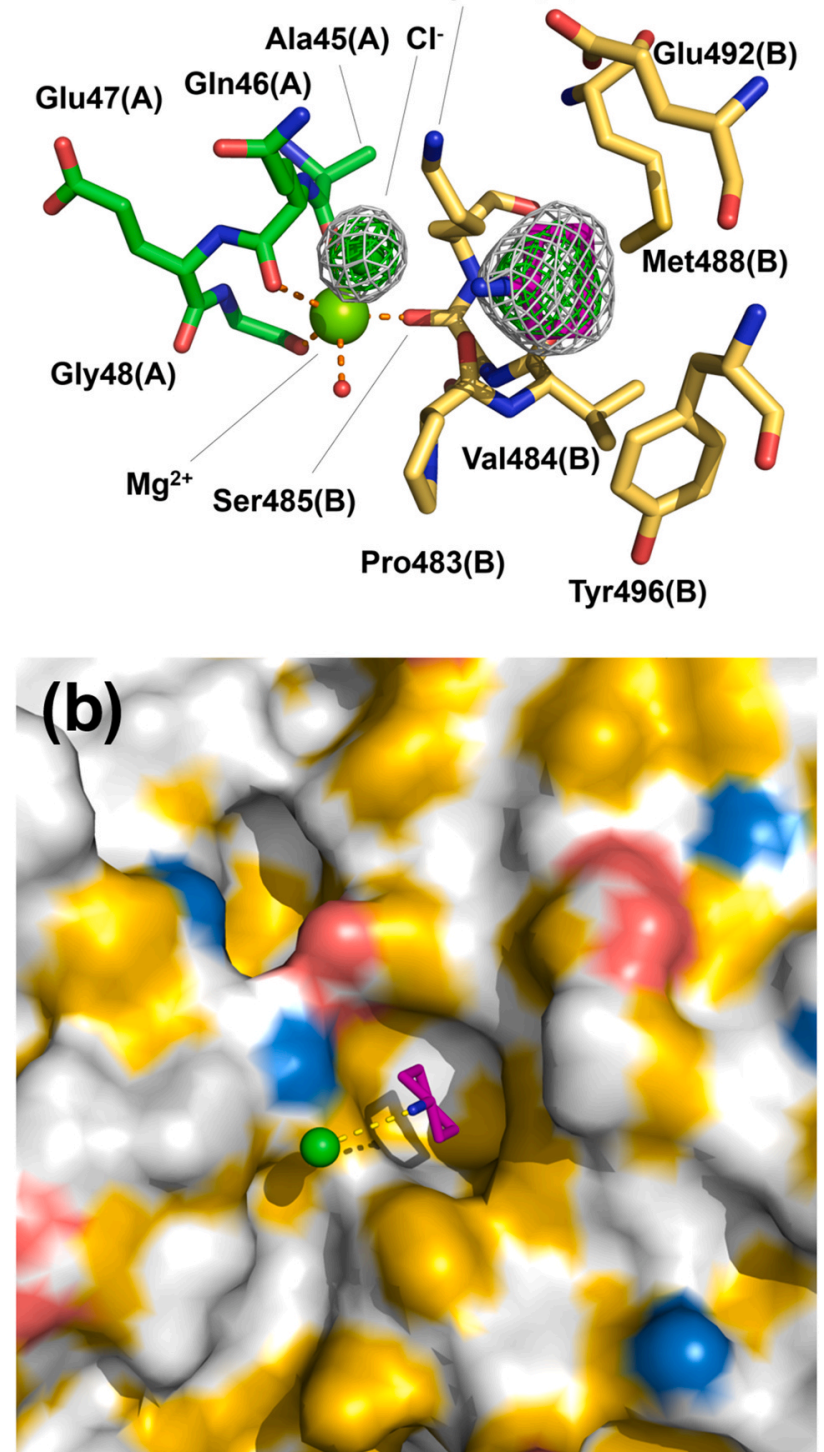

(c)
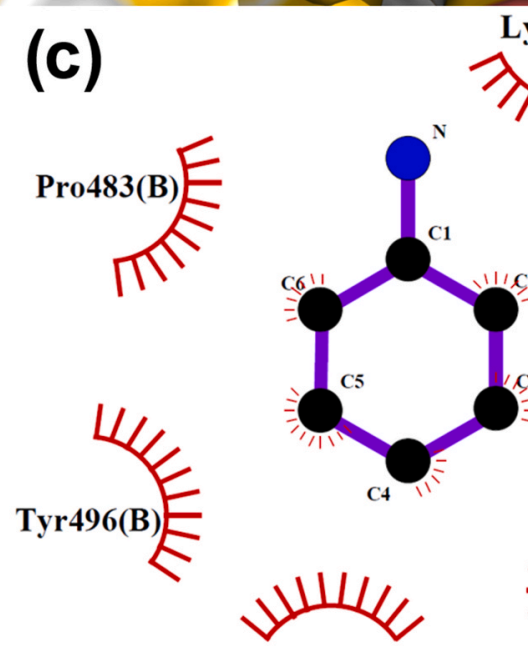

Lys486(B)

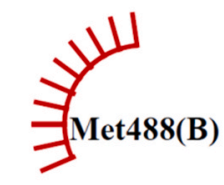

Val484(B)
Fig. 6. Binding of cyclohexylamine in the surface site of the A subunit in VAP. Cyclohexylamine bound on the surface of the VAP dimer in an identical manner on both subunits. (a) Coordination is mostly via hydrophobic interactions with Pro483, Val484, Lys486, Met488, Glu492 and Tyr496. Additional coordination came from a chloride ion positioned $3.5 \AA$ from the ammonium group of the ligand, which was further coordinated by Lys 486 via a distance of $3.9 \AA$. Furthermore, the chloride ion was observed in proximity (6.9 $\AA$ ) to the newfound dimer interface magnesium ion. The magnesium ion was pentacoordinated by the backbone carbonyl groups of Ala45(A), Gln46(A), Gly48(A) and Ser485(B) in trigonal bipyramid geometry. The binding was symmetrical on both sides of the dimer. The bound cyclohexylamine is shown as magenta and blue sticks, and selected water molecules are shown as red spheres. The refined $2 \mathrm{mF}_{\mathrm{o}}-\mathrm{F}_{\mathrm{c}}$ map (grey) is contoured at $1 \sigma$ and the SA Fo-Fc omit map (green) at $4.5 \sigma$. (b) The surface of the protein colored according to the YRB coloring scheme to illustrate the hydrophobic nature of the binding pocket. (c) A ligand plot illustrating the hydrophobic interactions of the ligand (For interpretation of the references to color in this figure legend, the reader is referred to the Web version of this article).

by a star, in line with an isomechanismic character and some previously suggested models implicating a structural change in the general reaction pathway for APs [50,56,57].

At alkaline $\mathrm{pH}$, the rate limiting step of AP catalysis is the dissociation of bound inorganic phosphate $\left(\mathrm{P}_{\mathrm{i}}\right)$ [58], and the reaction mechanism has previously been postulated to be of isoenzymatic nature, involving conformational changes between high and low affinity states to facilitate product release and substrate binding [57]. As mentioned above, the presence of $P_{i}$ in the active sites of the enzyme indicates that this crystal structure represents the non-covalent enzyme-product $\left(\mathrm{E} \cdot \mathrm{P}_{\mathrm{i}}\right)$ complex. The structural analysis showed that active site binding of cyclohexylamine was in large part coordinated directly by the bound phosphate ion via charge-charge interactions. Therefore, the active site binding of cyclohexylamine possibly occurs only in the enzyme-product complex with the bound phosphate as a necessary co-inhibitor. This could result both in retardation of product release, as the inhibitor blocks the path of the product out of the active site (Fig. 5c), or in impairment of a conformational change needed for product release. Cyclohexylamine did not affect substrate binding, as the $\mathrm{K}_{\mathrm{m}}$ value remained unchanged, and therefore, does likely not bind to the free enzyme species in the same manner as p-nitrophenyl phosphate. However, the binding together of cyclohexylamine and the substrate in the active site of the free enzyme species, to form a ternary enzyme-substrate-inhibitor complex, is a possibility.

The second binding site of the inhibitor (Fig. 6) was found on the surface of the protein, in proximity to the dimer interface, in a small peripheral hydrophobic binding pocket $20 \AA$ from the nucleophilic Ser65. The binding occurred almost exclusively through hydrophobic packing, with the addition of a coordinating chloride ion. When the inhibition of VAP by cyclohexylamine was measured at $\mathrm{pH}$ 8.0, with or without $0.5 \mathrm{M} \mathrm{NaCl}$, little variation was observed (Fig. 3b). Therefore, the binding of cyclohexylamine seems not to depend on the prior binding of chloride. As noted above, inter-subunit interactions are important for maintaining the active conformation of the AP dimer and subunit communication are likely to be involved in the catalytic cycle $[32,36]$. Cyclohexylamine binding distally from the active site could affect inter-subunit interactions, or conformational changes involved in catalysis. However, the binding interactions appeared weaker than in the active site due to lack of the ionic contribution and changes in residue 274 in the active site affected affinity for the inhibitor.

Mammalian alkaline phosphatases are allosteric enzymes which are inhibited in an uncompetitive manner by L-amino acids. This likely serves a downregulating function in vivo [59,60]. A crystal structure of the human placental AP (PLAP) with bound L-phenylalanine (L-Phe) revealed two distinct binding sites of the inhibitor involving the covalent phosphoenzyme intermediate [61]. Firstly, L-Phe bound in a small, hydrophobic and peripheral surface site on the $\alpha / \beta$-domain of the 


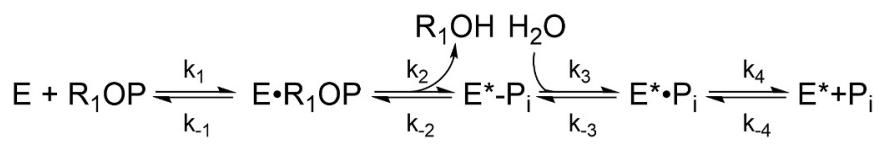

Scheme 1. Reaction mechanism of VAP indicating two structural states of the dimer, $\mathrm{E}$ and $\mathrm{E}^{*}$

protein, located $26 \AA$ from the nucleophilic Ser92 in the active site (Ser65 in VAP). Secondly, L-Phe was bound in the active sites of the enzyme. The active site binding occurred in large part via charge-charge interactions between the amino group of L-Phe and the phosphoserine reaction intermediate, in addition to hydrophobic interactions with Tyr367 (homologous to Tyr325 in VAP). The binding mode of L-Phe is highly similar to the active-site binding of cyclohexylamine to VAP (Fig. 7). Recent results from our group have shown that L-Phe is in fact a mixed-type inhibitor $(\alpha \neq 1)$ of VAP, with a $\mathrm{K}_{\mathrm{i}}$ of $54.2 \mathrm{mM}$ at $\mathrm{pH} 9.8$ (Unpublished results; B. Ásgeirsson and G. Jónsdóttir). This is in a similar range to the value observed for cyclohexylamine here (45.3 $\mathrm{mM})$. Additionally, the inhibitory effect of L-Phe decreased in VAP mutants W274A, W274K and W274H, to a similar extent as observed here with cyclohexylamine, further supporting the similarities between cyclohexylamine and L-Phe binding. Tyr325 in VAP (Tyr367 in PLAP) is a highly conserved AP residue, as a tyrosine residue is found in the equivalent position in all known APs except for ECAP [62]. This residue reaches into the active site of the other monomer and has previously been postulated to be important for inter-subunit interactions [31]. Therefore, the binding of cyclohexylamine to VAP could possibly

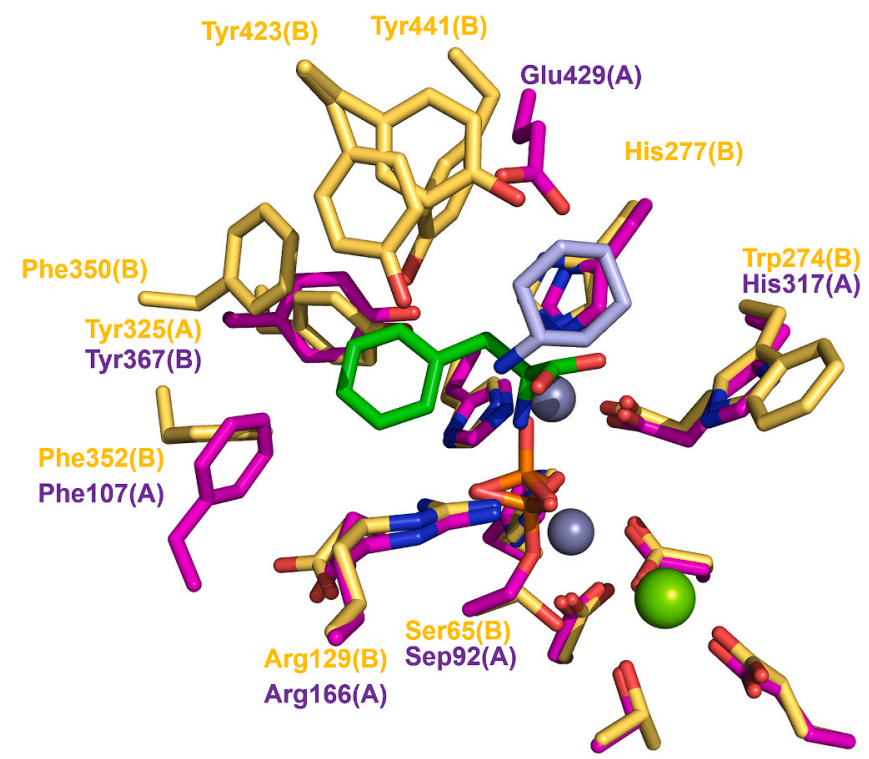

Fig. 7. Active site binding of L-phenylalanine to human placental AP resembles that of cyclohexylamine to VAP. L-Phe is an uncompetitive inhibitor of human placental alkaline phosphatase (PLAP) (PDB: 1 ZEF, [61]). Shown are the active sites of PLAP (magenta sticks) and VAP (yellow sticks) aligned. All residues within $4 \AA$ of the two ligands in the alignment are shown, as are metal coordinating residues. L-Phe (shown in green) binds only in the active site of the covalent phosphoenzyme intermediate in PLAP (in the form of phosphoserine-92; Sep92). L-Phe is mainly bound via hydrophobic interactions with the inter-subunit Tyr367 (homologous to Tyr325 in VAP). The amino group of L-Phe is seen in electrostatic interactions with the phosphoserine. Similarly, the binding of cyclohexylamine (light blue sticks) to VAP occurs only in the presence of bound inorganic phosphate. All L-Phe binding residues of PLAP are conserved in VAP, and a similar binding mode of L-Phe could be expected in VAP. The two active site zinc ions are shown as grey spheres and the magnesium ion as a green sphere. (For interpretation of the references to color in this figure legend, the reader is referred to the Web version of this article.) suggest a regulatory role of Tyr325. Further work would be required to confirm its regulatory role in VAP.

\subsection{Inhibitory effects on AP variants and VAP homologs}

We previously reported that the kinetic effect of replacing W274 in the VAP's active site with lysine found in ECAP (K274) was to reduce the overall reaction rate $\left(\mathrm{k}_{\mathrm{cat}}\right)$ to $15-30 \%$ of wild-type with a slight reduction in substrate affinity under similar hydrolyzing conditions as used here [33,34]. For the W274H variant, previous results indicated an unchanged $\mathrm{K}_{\mathrm{m}}$ value, but $50 \%$ reduction in $\mathrm{k}_{\mathrm{cat}}$ [34]. The prominent interaction with Trp274 in the active site as summarized by the LigPlot scheme (Fig. 5c) was supported with experimental results as a decrease in the inhibitory effect was observed upon replacing Trp274 via site-directed mutagenesis with alanine, lysine or histidine.

The inhibition by cyclohexylamine of other APs was also evaluated in this work. The analysis showed that AP from the Antarctic TAB5 bacterium was inhibited to a similar extend as VAP, but ECAP and calfintestinal alkaline phosphatase (CAP) were not. Whereas the structure of CAP is not known, the crystal structures of both ECAP and TAB5 AP have been solved $[63,64]$. Most of the residues mentioned above for inhibitor binding to VAP (Trp274, Tyr325 and His277) are found in the active site of TAB5 AP (Trp260, Tyr325 and His263) with the exception of Tyr441, being in an insert sequence in VAP. Thus, a similar binding mode could be expected in TAB5 AP as in VAP. In ECAP, only the zinc ligand His331 is shared, being homologous to His277 of VAP.

\section{Database linking and accession numbers}

IUBMB Enzyme Nomenclature: EC 3.1.3.1.

Protein Data Bank: X-ray crystal structure of Vibrio alkaline phosphatase with the non-competitive inhibitor cyclohexylamine (PDB ID: 6T26).

\section{Author contributions statement}

BA, RH and JGH conceived and supervised the study; BA, SSH, SM and JGH designed experiments; BA, SM, SSH and JGH performed experiments; BA, SM, SSH, RH and JGH analyzed data; BA wrote the original draft manuscript; $\mathrm{SM}, \mathrm{SSH}, \mathrm{RH}$ and JGH made manuscript revisions.

\section{Declaration of competing interest}

The authors declare that they have no known competing financial interests or personal relationships that could have appeared to influence the work reported in this paper.

\section{Acknowledgements}

Financial support from the Icelandic Centre for Research Fund (project 141619-053) and the Science Institute of the University of Iceland is gratefully acknowledged. The authors also thank Dr. Bjarte Aarmo Lund, Department of Chemistry, Faculty of Science and Technology at UiT - The Arctic University of Norway, NO-9037 Troms $\varnothing$, Norway, for expert assistance with protein crystallographic data collection, refinement and analyses. Furthermore, the authors would like to thank Prof. Petri Kursula and Dr. Arne Raasakka, Department of Biomedicine, University of Bergen, for their help with crystallographic refinement and data processing. The authors further acknowledge the use of beamtime at the BioMAX beamline at MAX IV Laboratory in Lund, SE with gratitude. 


\section{References}

[1] R.B. McComb, G.N. Bowers, S. Posen, Alkaline Phosphatase, Plenum Press, New York, 1979.

[2] J.M. Bates, J. Akerlund, E. Mittge, K. Guillemin, Intestinal alkaline phosphatase detoxifies lipopolysaccharide and prevents inflammation in zebrafish in response to the gut microbiota, Cell Host Microbe 2 (2007) 371-382.

[3] M.S. Malo, S.N. Alam, G. Mostafa, S.J. Zeller, P.V. Johnson, N. Mohammad, K. T. Chen, A.K. Moss, S. Ramasamy, A. Faruqui, S. Hodin, P.S. Malo, F. Ebrahimi, B. Biswas, S. Narisawa, J.L. Millan, H.S. Warren, J.B. Kaplan, C.L. Kitts, E. L. Hohmann, R.A. Hodin, Intestinal alkaline phosphatase preserves the normal homeostasis of gut microbiota, Gut 59 (2010) 1476-1484.

[4] J.P. Lalles, Intestinal alkaline phosphatase: novel functions and protective effects, Nutr. Rev. 72 (2014) 82-94.

[5] J. Bilski, A. Mazur-Bialy, D. Wojcik, J. Zahradnik-Bilska, B. Brzozowski, M. Magierowski, T. Mach, K. Magierowska, T. Brzozowski, The Role of Intestinal Alkaline Phosphatase in Inflammatory Disorders of Gastrointestinal Tract, Mediators Inflamm, 2017, 9074601. https://doi.org/10.1155/2017/9074601.

[6] K. Kaliannan, S.R. Hamarneh, K.P. Economopoulos, S. Nasrin Alam, O. Moaven, P. Patel, N.S. Malo, M. Ray, S.M. Abtahi, N. Muhammad, A. Raychowdhury, A. Fau Teshager, M.M.R. Mohamed, A.K. Moss, R. Ahmed, S. Hakimian, S. Narisawa, J. L. Millan, E. Hohmann, H.S. Warren, A.K. Bhan, M.S. Malo, R.A. Hodin, Intestina alkaline phosphatase prevents metabolic syndrome in mice, Proc. Natl. Acad. Sci. U.S.A. 110 (2013) 7003-7008.

[7] J. Fawley, D.M. Gourlay, Intestinal alkaline phosphatase: a summary of its role in clinical disease, J. Surg. Res. 202 (2016) 225-234.

[8] S.K. Kunutsor, T.A. Apekey, H. Khan, Liver enzymes and risk of cardiovascular disease in the general population: a meta-analysis of prospective cohort studies, Atherosclerosis 236 (2014) 7-17.

[9] M. Tonelli, G. Curhan, M. Pfeffer, F. Sacks, R. Thadhani, M.L. Melamed, N. Wiebe P. Muntner, Relation between alkaline phosphatase, serum phosphate, and allcause or cardiovascular mortality, Circulation 120 (2009) 1784-1792.

[10] C.R. Sheen, P. Kuss, S. Narisawa, M.C. Yadav, J. Nigro, W. Wang, T.N. Chhea, E. A. Sergienko, K. Kapoor, M.R. Jackson, M.F. Hoylaerts, A.B. Pinkerton, W. C. O'Neill, J.L. Millan, Pathophysiological role of vascular smooth muscle alkaline phosphatase in medial artery calcification, J. Bone Miner. Res. 30 (2015) 824-836.

[11] M. Schoppet, C.M. Shanahan, Role for alkaline phosphatase as an inducer of vascular calcification in renal failure? Kidney Int. 73 (2008) 989-991.

[12] M. Diaz-Hernandez, A. Gomez-Ramos, A. Rubio, R. Gomez-Villafuertes, J. R. Naranjo, M.T. Miras-Portugal, J. Avila, Tissue-nonspecific alkaline phosphatase promotes the neurotoxicity effect of extracellular tau, J. Biol. Chem. 285 (2010) 32539-32548.

[13] A.F. Pike, N.I. Kramer, B.J. Blaauboer, W. Seinen, R. Brands, An alkaline phosphatase transport mechanism in the pathogenesis of Alzheimer's disease and neurodegeneration, Chem. Biol. Interact. 226 (2015) 30-39.

[14] K.A.B. Kellett, N.M. Hooper, The role of tissue non-specific alkaline phosphatase (TNAP) in neurodegenerative diseases: Alzheimer's disease in the focus, Subcell. Biochem. 76 (2015) 363-374.

[15] T. Kiffer-Moreira, C.R. Sheen, K.C. Gasque, M. Bolean, P. Ciancaglini, A. van Elsas, M.F. Hoylaerts, J.L. Millan, Catalytic signature of a heat-stable, chimeric human alkaline phosphatase with therapeutic potential, Plos One 9 (2014), e89374.

[16] J.L. Millán, Alkaline Phosphatases : structure, substrate specificity and functiona relatedness to other members of a large superfamily of enzymes, Purinergic Signal. 2 (2006) 335-341.

[17] J.L. Millán, Mammalian Alkaline Phosphatases: from Biology to Applications in Medicine and Biotechnology, Wiley-VCH Verlag, Weinheim, 2006.

[18] J.L. Millán, M.P. Whyte, Alkaline phosphatase and hypophosphatasia, Calcif. Tissue Int. 98 (2016) 398-416.

[19] A. Garen, H. Echols, Properties of two regulating genes for alkaline phosphatase, J. Bacteriol. 83 (1962) 297-300.

[20] R.J. Scheibe, H. Kuehl, S. Krautwald, J.D. Meissner, W.H. Mueller, Ecto-alkaline phosphatase activity identified at physiological pH range on intact P19 and HL-60 cells is induced by retinoic acid, J. Cell. Biochem. 76 (2000) 420-436.

[21] M. Du, X. Li, Z. Li, Q. Shen, Y. Wang, G. Li, D. Zhang, Phosphorylation regulated by protein kinase $\mathrm{A}$ and alkaline phosphatase play positive roles in mu-calpain activity, Food Chem. Toxicol. 252 (2018) 33-39.

[22] H. Zhou, Z.G. Han, T. Fang, Y.Y. Chen, S.B. Ning, Y.T. Gan, D.Z. Yan, Characterization of a new cyclohexylamine oxidase from Acinetobacter sp. YT-02, Front. Microbiol. 9 (2018) 1-9.

[23] A. Khadem, F. Raiesi, Response of soil alkaline phosphatase to biocha amendments: changes in kinetic and thermodynamic characteristics, Geoderma 337 (2019) 44-54.

[24] R. Mariya al, I. Jamshed, Inhibition of alkaline phosphatase: an emerging new drug target, Mini Rev. Med. Chem. 15 (2015) 41-51.

[25] W.H. Fishman, H.G. Sie, Organ-specific inhibition of human alkaline phosphatase isoenzymes of liver, bone, intestine and placenta; L-phenylalanine, L-tryptophan and L homoarginine, Enzymologia 41 (1971) 141-167.

[26] R.L. Dean, Kinetic studies with alkaline phosphatase in the presence and absence of inhibitors and divalent cations, Biochem. Mol. Biol. Educ. 30 (2002) 401-407.

[27] S. Chakraborty, B. Ásgeirsson, R. Minda, L. Salaye, J.-M. Frère, B.J. Rao, Inhibition of a cold-active alkaline phosphatase by imipenem revealed by in silico modeling of metallo-beta-lactamase active sites, FEBS Lett. 586 (2012) 3710-3715.

[28] J. Iqbal, M.I. El-Gamal, S.A. Ejaz, J. Lecka, J. Sevigny, C.H. Oh, Tricyclic coumarin sulphonate derivatives with alkaline phosphatase inhibitory effects: in vitro and docking studies, J. Enzym. Inhib. Med. Chem. 33 (2018) 479-484.
[29] A.B. Pinkerton, E. Sergienko, Y. Bravo, R. Dahl, C.T. Ma, Q. Sun, M.R. Jackson, N. D.P. Cosford, J.L. Millan, Discovery of 5-((5-chloro-2-methoxyphenyl)sulfonamido) nicotinamide (SBI-425), a potent and orally bioavailable tissue-nonspecific alkaline phosphatase (TNAP) inhibitor, Bioorg Medicinal Chem Lett, 2017.

[30] J. Hauksson, O. Andrésson, B. Ásgeirsson, Heat-labile bacterial alkaline phosphatase from a marine Vibrio sp. Enzym. Microb. Technol. 27 (2000) 66-73.

[31] R. Helland, R.L. Larsen, B. Ásgeirsson, The $1.4 \AA$ crystal structure of the large and cold-active Vibrio sp. alkaline phosphatase, Biochim. Biophys. Acta 1794 (2009) 297-308.

[32] J.G. Hjörleifsson, B. Ásgeirsson, Cold-active alkaline phosphatase is irreversibly transformed into an inactive dimer by low urea concentrations, Biochim. Biophys. Acta Protein Struct. Mol. Enzymol. 1864 (2016) 755-765.

[33] K. Gudjonsdottir, B. Asgeirsson, Effects of replacing active site residues in a coldactive alkaline phosphatase with those found in its mesophilic counterpart from Escherichia coli, FEBS J. 275 (2008) 117-127.

[34] P.O. Heidarsson, S.T. Sigurdsson, B. Ásgeirsson, Structural features and dynamics of a cold-adapted alkaline phosphatase studied by EPR spectroscopy, FEBS J. 276 (2009) 2725-2735.

[35] R.A. Copeland, Enzymes: A Practical Introduction to Structure, Mechanism, and Data Analysis, second ed., Wiley-VCH, NJ, 2000.

[36] J.G. Hjörleifsson, B. Ásgeirsson, pH-dependent binding of chloride to a marine alkaline phosphatase affects the catalysis, active site stability, and dimer equilibrium, Biochemistry 56 (2017) 5075-5089.

[37] J.L. Sebaugh, Guidelines for accurate $\mathrm{EC}_{50} / \mathrm{IC}_{50}$ estimation, Pharmaceut. Stat. 10 (2011) 128-134.

[38] P. Brandt, C. Woodward, Hydrogen exchange kinetics of bovine pancreatic trypsin inhibitor beta-sheet protons in trypsin-bovine pancreatic trypsin inhibitor, trypsinogen-bovine pancreatic trypsin inhibitor, and trypsinogen-isoleucylvalinebovine pancreatic trypsin inhibitors, Biochemistry 26 (1987) 3156-3162.

[39] W. Kabsch, Xds, Acta Crystallogr. D 66 (2010) 125-132.

[40] P.R. Evans, G.N. Murshudov, How good are my data and what is the resolution? Acta Crystallogr. D 69 (2013) 1204-1214.

[41] A.J. Mccoy, R.W. Grosse-Kunstleve, P.D. Adams, M.D. Winn, L.C. Storoni, R. J. Read, Phaser crystallographic software, J. Appl. Crystallogr. 40 (2007) 658-674.

[42] P.D. Adams, P.V. Afonine, G. Bunkoczi, V.B. Chen, I.W. Davis, N. Echols, J. J. Headd, L.W. Hung, G.J. Kapral, R.W. Grosse-Kunstleve, A.J. McCoy, N. W. Moriarty, R. Oeffner, R.J. Read, D.C. Richardson, J.S. Richardson, T. C. Terwilliger, P.H. Zwart, PHENIX: a comprehensive Python-based system for macromolecular structure solution, Acta Crystallogr Section D-Structural Biology 66 (2010) 213-221.

[43] P.V. Afonine, R.W. Grosse-Kunstleve, N. Echols, J.J. Headd, N.W. Moriarty, M. Mustyakimov, T.C. Terwilliger, A. Urzhumtsev, P.H. Zwart, P.D. Adams, Towards automated crystallographic structure refinement with phenix.refine, Acta Crystallogr Section D-Structural Biology 68 (2012) 352-367.

[44] P. Emsley, K. Cowtan, Coot: model-building tools for molecular graphics, Acta Crystallogr D Biol Crystallogr 60 (2004) 2126-2132.

[45] V.B. Chen, W.B. Arendall, J.J. Headd, D.A. Keedy, R.M. Immormino, G.J. Kapral, L. W. Murray, J.S. Richardson, D.C. Richardson, MolProbity: all-atom structure validation for macromolecular crystallography, Acta Crystallogr Section DStructural Biology 66 (2010) 12-21.

[46] L. Schrodinger, The PyMOL Molecular Graphics System, 2019, Version 2.3.

[47] I.H. Segel, Biochemical Calculations: How to Solve Mathematical Problems in General Biochemistry, second ed., John Wiley \& Sons, Inc., 1976.

[48] S. Arai, Y. Yonezawa, M. Ishibashi, F. Matsumoto, M. Adachi, T. Tamada, H. Tokunaga, M. Blaber, M. Tokunaga, R. Kuroki, Structural characteristics of alkaline phosphatase from the moderately halophilic bacterium Halomonas sp. 593, Acta Crystallogr. D: Biol Crystallogr. 70 (2014) 811-820.

[49] M. Rina, C. Pozidis, K. Mavromatis, M. Tzanodaskalaki, M. Kokkinidis, V. Bouriotis, Alkaline phosphatase from the Antarctic strain TAB5 properties and psychrophilic adaptations, Eur. J. Biochem. 267 (2000) 1230-1238.

[50] S.E. Halford, N.G. Bennett, D.R. Trentham, H. Gutfeund, A substate-induced conformation change in the reaction of alkaline phosphatase from Escherichia coli, Biochem. J. 114 (1969) 243-251.

[51] Sajid-ur-Rehman, A. Saeed, G. Saddique, P. Ali Channar, F. Ali Larik, Q. Abbas, M. Hassan, H. Raza, T.A. Fattah, S.-Y. Seo, Synthesis of sulfadiazinyl acyl/aryl thiourea derivatives as calf intestinal alkaline phosphatase inhibitors, pharmacokinetic properties, lead optimization, Lineweaver-Burk plot evaluation and binding analysis, Bioorg. Med. Chem. 26 (2018) 3707-3715.

[52] R.B. Silverman, Organic Chemistry of Enzyme-Catalyzed Reactions, second ed. ed., Academic Press, New York, 2002.

[53] K.L. Rebholz, D.B. Northrop, Kinetics of iso mechanisms, Enzyme Kinetics and Mechanism, Pt D 249 (1995) 211-240.

[54] Y. Blat, Non-competitive inhibition by active site binders, Chem. Biol. Drug Des. 75 (2010) 535-540.

[55] R.A. Copeland, Evalutaion of Enzyme Inhibitors in Drug Discovery: A Guide for Medicinal Chemists and Pharmacologists, Wiley-VCH, Hoboken, New Jersey, 2013.

[56] S. Orhanovic, M. Pavela-Vrancic, M. Flogel-Mrsic, Evidence for assymmetry of alkaline phosphatase from E. coli, Acta Pharm. 44 (1994) 87-95.

[57] S. Orhanovic, M. Pavela-Vrancic, Dimer asymmetry and the catalytic cycle of alkaline phosphatase from Escherichia coli, Eur. J. Biochem. 270 (2003) 4356-4364.

[58] P.W. Whitby, M. Landon, G. Coleman, The cloning and nucleotide sequence of the serine protease gene (aspA) of Aeromonas salmonicida ssp salmonicida, FEMS Microbiol. Lett. 99 (1992) 65-72.

[59] M.F. Hoylaerts, T. Manes, J.L. Millan, Mammalian alkaline phosphatases are allosteric enzymes, J. Biol. Chem. 272 (1997) 22781-22787. 
[60] M.F. Hoylaerts, T. Manes, J.L. Millan, Molecular mechanism of uncompetitive inhibition of human placental and germ-cell alkaline phosphatase, Biochem. J. 286 (Pt 1) (1992) 23-30.

[61] P. Llinas, E.A. Stura, A. Menez, Z. Kiss, T. Stigbrand, J.L. Millan, M.H. Le Du, Structural studies of human placental alkaline phosphatase in complex with functional ligands, J. Mol. Biol. 350 (2005) 441-451.

[62] A. Kozlenkov, T. Manes, M.F. Hoylaerts, J.L. Millán, Function assignment to conserved residues in mammalian alkaline phosphatases, J. Biol. Chem. 277 (2002) $22992-22999$.

[63] E. Wang, D. Koutsioulis, H.K. Leiros, O.A. Andersen, V. Bouriotis, E. Hough, P. Heikinheimo, Crystal structure of alkaline phosphatase from the Antarctic bacterium TAB5, J. Mol. Biol. 366 (2007) 1318-1331.
[64] E. Bobyr, J.K. Lassila, H.I. Wiersma-Koch, T.D. Fenn, J.J. Lee, I. Nikolic-Hughes, K. O. Hodgson, D.C. Rees, B. Hedman, D. Herschlag, High-resolution analysis of $\mathrm{Zn}^{2+}$ coordination in the alkaline phosphatase superfamily by EXAFS and X-ray crystallography, J. Mol. Biol. 415 (2012) 102-117.

[65] A.C. Wallace, R.A. Laskowski, J. Singh, J.M. Thornton, Molecular recognition by proteins: protein-ligand interactions from a structural perspective, Biochem. Soc. Trans. 24 (1996) 280-284.

[66] D. Hagemans, I.A.E.M. van Belzen, T.M. Luengo, S.G.D. Rüdiger, A script to highlight hydrophobicity and charge on protein surfaces, Front Mol Biosci (2015), https://doi.org/10.3389/fmolb.2015.00056. 